Etica \& Politica / Ethics \& Politics, 2005, 2

http://www.units.it/etica/2005_2/TURNER.htm

\title{
The Continued Relevance of Weber's Philosophy of Social Science
}

$\underline{\text { Stephen Turner }}$

Center for Social and Political Thought

University of South Florida

\begin{abstract}
Only a few writers have attempted to construct a comprehensive philosophy of social science, and of these Weber is the most relevant to the present. The structure of his conception places him in a close relationship to Donald Davidson. The basic reasoning of Davidson on action explanation, anomalous monism, and the impossibility of a "serious science" of psychology is paralleled in Weber. There are apparent differences with respect to their treatment of the status of the model of rational action and the problem of other cultures, as well as the problem of the objectivity of values, but on examination, these turn out to be less dramatic. Weber's use of the notion of ideal-types, though it is not paralleled as directly in Davidson, allows him to make parallel conclusions about the relation of truth and interpretation: both make the problem of intelligibility rather than correspondence with some sort of external reality central, and each addresses, though in different ways, the dependence of considerations of intelligibility on normativity and the impossibility of a theory of meaning without idealization.
\end{abstract}

Methodological and philosophical writings about the social sciences are plagued by the eternal recurrence, typically in slightly different guises, of the same issues: abstraction, rationality and its relevance to causal explanation, the problem of cultural and historically specific perspectives as a condition for constituting and defining topics and the problem of reconciling this with claims to universality of knowledge, and various other problems relating to the question of the a priori conditions of knowledge itself, which in the social sciences often involves conflicting choices between possible starting points. Dealing with any of these complex issues as they relate to the polymorphous and pluralized disciplinary and subject-matter worlds of the humanities and human sciences is difficult. But attaining some sort of reasonable perspective on the relations of these problems to one another, and in addition to the problem of the relations between the human sciences and such related 
enterprises as the natural sciences and the normative disciplines, for example law, is overwhelmingly difficult.

The thinkers who have attempted to deal with these problems by reductive simplifications are numerous. The thinkers who have seriously attempted to deal with all of them are few. One of them was John Stuart Mill, and the tremendous influence of his major work on the philosophy of social science, his System of Logic, (1) testifies both to the difficulty of the task, with which he only partially succeeded, and the rarity with which it is attempted. Weber is perhaps the only other thinker who has left a coherent response to these issues which deals with the relations between these issues. Weber's competitors in his own time, such as Durkheim, Pareto and Karl Pearson, whose methodological ideas were transmitted and refined for social science by Franklin Giddings in the United States, each dealt with some of these issues but ignored, dismissed, or made arbitrary choices with respect to others.

In what follows I will explain Weber's views on each of these issues and the ways he put them together. In my conclusion, I will indicate some ways in which these issues remain live problems and also why some of the favored present day solutions to these problems in contemporary philosophy are inadequate or at least problematic. My stalking horse in this discussion will be, perhaps surprisingly, Donald Davidson, who is among the few contemporary philosophers to attempt to deal with what is roughly the same range of problems, especially problems of the nature of rationality as a model, the role of the normative in the constitution of problems, including the problem of rationality, and the dubiousness of such collective concepts as language. Davidson contrasts to Weber on these key issues, issues which are important to present philosophy, and are especially important in the interface between contemporary philosophy and the philosophy of social science.

What may seen odd about this discussion is that Davidson is an "analytic" philosopher, while Weber is and has usually been understood in terms of continental philosophy. The great works on Weber as a philosopher, such as Bruun's Science, Values and Politics in Max Weber's Methodology (1971), (2) Leo Strauss's treatment of Weber in Natural Right and History (1953),(3) or Schutz's Phenomenology of the Social World (1932),(4) have generally taken Weber as a part of this tradition. But today, especially in the light of Michael Friedman's work on the origins of Logical Positivism and on the parting of the ways between what became "Continental" and "analytic" philosophy, (5) which occurred for the most part after Weber wrote, these contrasts no longer have the categorical meaning they once did. And the rise of rational-choice theorizing and its application to Weber has closed the gap further: Richard von Mises' "Austrian Economics" critique of Weber, ()ㅡ as we shall see, is 
as relevant today as ever- and the issues over the status of the model of rational choice that arise with Mises are also issues that are at the heart of the comparison to Davidson.

\section{Reasons and Causes}

Weber understood at the outset that there was a fundamental conflict between the task of understanding action and the task of causal explanation, but he also understood that the conflict could not be resolved by collapsing one into the other. Reasons were not causes, at least in the sense of cause as governed by scientific laws, if these were understood on analogy with laws of chemistry, physics, or astronomy. The concepts we employ in the natural sciences, are, so to speak, developed to fit and explain the irregularities that science discovers. In social science, in contrast, the terms in which we describe the things we wish to explain are given for us in what Weber characterizes as the language of life.(7) There is no a priori reason that this is true, but it nevertheless is true: there are no nomic regularities that correspond to the facts that can be described in the language of life.

Nevertheless, causal explanation is part and parcel to some extent of all of the human sciences, or as Weber typically calls them, the historical sciences, even where these sciences are constituted and define themselves in such a way as to minimize the significance of causality. Weber resolves this conflict by arguing that there is a different relevant notion of causality, which he identifies with a very specific legal theory of causal explanation developed by his Freiburg colleague, Johannes von Kries. (8)

This account defines "adequate causation" as an increase in the probability of an event if we compares the probability of the event given the cause in question together with a selected set of background causes and the probability of the event given the background causes on their own.

Von Kries provides him with a plausible and easily generalized notion of causality that does not depend on the existence of genuine regularities and is entirely consistent with the formulation of both input and output causes and outcomes in "the language of life." It is a method that allows us to speak of causes of the kind familiar to the historian, such as the causes of World War I, but also allows us to speak of the causal contribution of such things as the reasons that a given person had which contributed to an action, such as the elements of a decision. The notion of cause here is not an experimental notion but rather one based on expectations derived from 
the ordinary course of events which are then applied to particular actions in order to make sense of them both "causally" and "rationally."

Weber's solution in principle to the problem of reasons and causes, then, is to require that an explanation of an action be "adequate" both at the level of understanding or interpretation, which is to say that it makes the action within its circumstances intelligible in terms of a type concept that is already understood, and adequate at the level of cause, which is to say, consistent with our expectations about the contribution of a particular reason as a cause in a set against the background of a similar set of circumstances or causal conditions.

Is this an adequate conception of action in contemporary terms? It compares to the writings of Donald Davidson on anomalous monism, $(9)$ though there are significant differences. Like Weber, Davidson argues that actions can be understood causally in terms of reasons together with what he calls pro-attitudes, which are motivational sources of varying strength. He says also that "reasons exlanations...are in some sense low-grade; they explain less than the best explanations in the hard sciences because of their relieance on propensities."(10) Davidson also acknowledges that the genuinely nomic causes of human action cannot be articulated within the language of life.(11) But unlike Weber, for whom the typification of rationality with respect to action is one, though the most useful and powerful, of a myriad of intelligibility producing typifications, such as the typification of actions done out of emotions (in which, for example, the evidence of an angry face, together with sufficient motivating circumstances, justifies the application of the typification "done out of anger"). For Weber, these various typifications are in effect on equal footing as intelligibility producers and potential causes, though obviously some will be more useful than others in particular contexts.

Weber does not deny that such things as biological causes are causal contributors to human action even when they are not part of the language of life or a typification of the kind that renders an action intelligible. When he comments that the facts described by the concept of charisma seem to fade off from the intelligible into the unintelligible, where they can best be accounted for as biologically caused phenomena, he acknowledges the limitations of the understanding of actions as actions, that is to say as fully intelligible, and he freely concedes that large areas of even intelligible action are co-produced by reasons or causes construed in the language of life and biological causes.

Davidson, in contrast, is committed to the indispensability of the paradigm of rational choice or decision theory treating it as inseparable from the notion of intelligibility and reasons with respect to human actions. This is to say that Weber accepts what 
we might call piecemeal intelligibility, intelligibility in terms of a variety of distinct typifications, while Davidson believes that the wholesale conception of rationality is necessary to the understanding of action. It should noted that Davidson's account, unlike Weber's, forces him into a series of questions about the status of decision theory as, so to speak, an a priori psychology and leads him to claim that it is both $a$ priori to and "empirical."

It also leaves Davidson, unlike Weber, with the problem of akrasia or weakness of will, a problem that arises from the ubiquitous gaps between the possession of reasons and actions. Akrasia is not a problem for Weber, for two reasons. Because Weber considers typifications of actions to be ideal-typical in character and therefore holds that the extent to which an apparent action is in fact an action is a matter of degree and fact rather than a matter that can be settled a priori. Moreover, akrasia is a familiar and intelligible phenomenon, which, in Weber's terms, we can typify. But in the end, the differences are limited. Davidson in his own way acknowledges the co-production of action by biology and reasons. $(12)$ He argues that his own account of the logic of action explanation, in which reasons together with a "proattitude" constitute the kind of "cause" appropriate to human action, is connected to the brain, which processes information and desire in two different places. Thus like Weber he grants that having a reason is not enough, and that the kind of cause appropriate to human action is not the same as that in the nomic sciences. But where Weber takes the view that in interpreting action, reasons and pro-attitudes are packaged together in typifications which make action intelligible, and that the probability of action outcomes is a separate issue, Davidson takes the view that the two elements of action- reasons and pro-attitudes- have distinct biological sources. Yet for both of them, these biological sources are unusable as action explanations because they are not in the language of life, and thus there is no possibility of reduction or "explanation" in the nomic sense. And for Weber, the probabilities of outcomes are potentially influenced by co-producers, such as the biological causes that contribute to charisma.

Whether one prefers to accept Weber's difficulties or Davidson's on this matter, it is relevant to note that the dispute over the status of what Weber thinks of as the ideal type of total rationality was well developed in Weber's own lifetime, and a contrast between the two was discussed by Alfred Schutz, who adhered to the position of von Mises, who identified action by definition with rational action and thus, like Davidson, denied that actions which could not be made intelligible in terms of rationality were, properly speaking, actions at all. Unlike Davidson, for Weber intelligibility in terms of typifications is not limited to what he treats as the 
"typification" of rational action, and the characteristic of "being an action" is a matter of degree.

One final similarity is in Davidson's and Weber's views of the empirical status of the model of rational choice. Davidson was involved in the continued discussion in the psychological field of decision science of the status of decision theory as a model of human decision-making, a literature faced with the problem that actual human decisions systematically vary from the "normative" model, which nevertheless seems to be $a$ priori valid. Davidson presents the issue in this way:

«It may seem that I want to insist that decision theory, like the simple postulate that people tend to do what they believe will promote their ends, is necessarily true, or perhaps analytic, or that it states part of what we mean by saying someone prefers one alternative to another. But in fact I want to say none of these things, if only because I understand none of them. My point is skeptical, and relative. I am skeptical that we have a clear idea of what would, or should, show that decision theory is false; and I think that compared to attributions of desires, preferences or beliefs, the axioms of decision theory lend little empirical force to explanations of action".(13)

Weber expressed this same sense that "rationality" was neither a priori nor empirical with his notion that rationality was an ideal-type. To put the problem in Weber's terms, the question is whether the ideal type "rationality" is merely a typification or is genuinely explanatory, in spite of its lack of correspondence to actual human decision making. It is notorious that Weber's uses of the term rationality were various, shifting, and irreducible to a single sense.

Davidson makes a related point when he says "The issue is not whether we all agree exactly on what the norms of rationality are; the point is rather that we all have such norms, and that we cannot recognize as thought phenomena that are too far out of the line. Better say: what is too far out of line is not thought". (14) Weber would reach the same conclusion by way of typification: action we cannot typify as action (including rational action) is, for us, not action.

\section{Models and Ideal-types}

Weber's use of the term ideal type and typification may appear to place him in the epistemic dark ages. Not only is this language no longer current, the neo-Kantian notions of concept and conceptualization from which it derives, such as Rickert's idea of the hiatus irrationalis between concept and reality, is no longer current. 
Nevertheless, the issues that Weber sought to address by the use of these terms are alive in contemporary philosophy. In the case of rationality, as we have seen, the issue is phrased in terms of normativity.

Decision theory is a "normative" conception whose empirical significance and thus its explanatory power is problematic. The question is whether the normative conception is in some sense indispensable or necessary for the constitution of the subject matter, for example, for the intelligible interpretation of the beliefs of other people, as Davidson suggests in "The very idea of a conceptual scheme".(15) Weber in his discussion of ideal types faced the problem of normativity in almost the same form, since he was compelled to distinguish the explanatory from the "dogmatic" uses of the same concept, and to explain that the unique ideal of rationality was abstract and therefore ideal in the sense of ideational rather than "normatively preferable." Weber gives, as an example, the problem of explaining the blunders made by a general in the battlefield, something that requires a model of correct decision making against which actual conduct could be compared to identify the blunder to be explained.

This approach was the one taken up by Popper in The Poverty of Historicism under the label of "the logic of the situation": that the normative conception can serve as a baseline for asking questions about the influences on action by allowing the analyst to see what produced deviations from "rationality".(16) This is an approach totally consistent with psychological decision theory, which treats deviations from the normative as "biases." But for Weber (unlike Popper), there is a rationale for treating the normative model (understood as an ideal-type), as a baseline: it is, as he argues, the most intelligible ideal-type, for us. Thus the justification for its use is purposerelative rather than a priori, and the purpose is central to the aims of historical science as an "understanding" discipline.

In this form, the consideration of normativity is irrelevant. Instead, the notion of ideal type compares closely to contemporary philosophy of science discussions of models, which similarly are both idealizations rather than law-like statements and useful both to make simplifications of complex situations in order to make predictions and to use these simplifications to identify sources of interference that may themselves have important, even overwhelming predictive significance.

As a construction (of such things as the patrimonial state, Cadi justice, or charismatic authority), an ideal-type implies nothing about their correspondence to reality, their actual predictive power, or their desirability as a state of affairs. The term "ideal" here implied merely that the type could be fully articulated as an idea and thus be able to be used to contrast to a complex and messy reality for various explanatory 
purposes. Deviations from the ideal might be as useful in defining explanatory issues as informative to an ideal.

The present relevance of Weber views on ideal types or models is, ironically, perhaps greater today than it has been for the rest of the intervening century, where social scientists, under the influence of the model of physical law and logical positivism, sought to construct "general theories" of societies as systems, or obsessed about the differences between reasons and causes. The notion of models or ideal types in Weber's hands cuts across these distinctions by, in the first place, treating reasons of particular types, typifications, which are usually mini-models, and by treating rationality itself as a model. This means that a model can be constructed of some phenomena, such as the disappearance of a type of money in a two currency system, the case covered by Gresham's law.

This is a model rather than a law. It predicts what will happen if people reasoned about the value of currency in particular ways and act on those reasons without interference by other reasons or causes. Here the explanatory part of the model is rationality, but rationality applied in a very specific setting, reduced to a very small number of rational considerations. But other models may be constructed that do not get organized around this element. Weber's model of the ancient city as discussed by M. I. Finley is such a model.(17) It is essentially a model of an ancient economy in terms of its inputs/outputs and the social and political structures that enable the economy to function.

The uses of such a model are multiple. It predicts, enables interpretation, enables comparisons that point to explanations of differences, and so forth, but it is explicitly a simplification, or abstraction, and thus not "true" but rather applicable to rich and complex situations where the richness is an unusable distraction which needs to be reduced, but which cannot be usefully reduced to scientific (or for that matter economic) "laws."

It was formerly thought that the sciences which were in a position to reduce the richness or complexity of the subject matter by constructing artificial experiments had the advantage over the social sciences, because experiments in a very simplified set of circumstances could be constructed to match up with the issues in crucial experiments between theories or for producing direct confirmation of theories. But generalizing from experiment is a problem that requires the richness of cases to be taken into account, and the only means for doing this is the construction of an intermediate abstraction, a model, for this purpose. These models may be made up of theoretical principles but they also (and often) involve interactions between variables whose properties are unpredicted by the theory but which can be estimated 
from the data itself. This puts social science and natural science on something closer to an equal epistemic footing, and at the same time rescues Weber's usage from the antique language in which it is presented.

\section{Cultural Categories}

Perhaps the most relevant of Weber's core ideas, which we have already alluded to, concerns the cultural constitution of the objects of social science.(18) Weber's methodological enemies divide into roughly two groups. One group believes that the cultural constitution of the subject matter is irrelevant as long as we can identify data points and treat these as facts which can be related statistically or in some other quantitative way. Durkheim's famous slogan, "treat social facts as things," is an expression of this impulse, but it appears in an even more unmediated form in standard social science methodology where any quantifiable material becomes, by virtue of its quantifiability, a potential subject of statistical analysis and "theory." The second group of Weber's enemies are what I will dub apriorist. The paradigm case of apriorism in the philosophy of social science is the distinction between reasons and causes itself, which grants a priori status of irreducibility, correctness, and descriptive validity to those descriptions of conduct or action which correspond to the reasons of the agent or of the agent's linguistic community, represented especially by Peter Winch.(19) There are however, many other a priori starting points. Von Mises' equation of rationality and action is one of them-- all actions are by definition rational and nothing that is not rational is properly speaking an action. Here we see the a priori structure in a particularly naked form.

But many other thinkers such as George Herbert Mead have constructed the problem of explaining human activity in terms of considerations that are also a priori. For Mead, the problem of priority is one in which particular features of human activity, such as symbol use, are taken for granted as valid descriptors and subjects to be explained, and the problem becomes to account for the conditions for the intelligible use of these concepts in analysis. Thus Mead criticized the a priori notion of the self by showing that others were a condition for the construction of the self. This style of analysis works fundamentally by taking some particular fact in the human realm as given, as Mead does, and inquiring into its conditions. Alfred Schutz, similarly, took human understanding of the other as the thing to be accounted for and inquired into the phenomenological conditions for such understanding.

Weber's response to all of this is to collapse the problem of the a priori into the 
problem of the arbitrariness of categories of, as he puts it, selection from the meaningless chaos of existential judgments that would face us if we approached reality "without presuppositions." $\underline{20)}$ His argument is that the social sciences have already had the selection made for them, in the first instance, by the constitution of the subject matter in the language of life. For him, the problem of understanding is a matter of our interest. We choose to be concerned with human things described in human language. Terms like "action" or "the city" are, initially at least, simply terms of common usage which constitute our subject matter for us. We then make further conceptual refinements in our selections from reality based on our specific explanatory interests.

For Weber, sociology itself is not, so to speak, a subject matter grounded in the nature of the universe but is rather grounded in the choices that we make to define the subject. His definition of sociology, as the study of meaningful social action, has no special status as a definition. It is not further grounded in an a priori, philosophically groundable ontology or epistemology which selects it as the only possible definition- something that many of his critics and interpreters, such as Schutz found to be a failing. Like the conceptual categories that Weber deploys, its only claim on us is the claim of utility, and utility is utility in reference to culturally generated and fundamentally ordinary kinds of purposes of understanding, such as the purpose of understanding the historical causes of present day capitalism, rather than, so to speak, universal epistemic goals, such as the final truth about the nature of society.

This is an important move because it temporalizes, historicizes, and makes culturally relative all of the problematic philosophical distinctions, even including the distinction between reasons and causes, which have been the subject of aprioristic philosophizing during the $20^{\text {th }}$ century. The significance of doing this is that it undermines any sort of absolutization of particular concepts. The notion of the self, for example, becomes available to us as a theoretical or conceptual term which we can use to define problems, but our use of it always comes with the implicit qualification that the term may be historically rooted in the language of life of a very specific historical community, ours, and that its applicability elsewhere cannot be taken for granted, and indeed that the applicability and historical origins and development of such concepts becomes fair game for sociological analysis itself. Thus the modern notion of the self is, as Weber implicitly treats it, the product of a particular theodicy that is part of the theology of reformation Protestantism, without which there would not be the concept of "the self" in its present form.

Philosophers have come very slowly to this appreciation of the pervasiveness of the 
problem of the historicity of concepts, in spite of the early recognition, at least within the Continental tradition, of the historical mutability even of such basic concepts as Being. More recently, philosophers such as Charles Taylor have developed philosophical analogues to the sociological stories that Weber tells, both with respect to the self, and with respect to modernity (21) in his book on modernity. It is evident that the same kinds of methodological issues, especially issues of differences in epistemic purposes, bear on the claims of these books and on their claim to improve upon and supplant Weber himself.

This strategy of historicization, applied reflexively, raises a question for Weber that was pointed out repeatedly by his critics in the twenties. Is Weber's own conception of social science transhistorical, and if so, how can the idea of a transhistorical conception of social science be understood within the framework of the purposerelative conception of social science in which fundamental conceptual schemes and categories are understood to be historical. His admirers, notably Karl Jaspers, argued that his conception of social science was itself purpose-relative, an instrument or a probe, which was itself subject to revision and which made no claim to finality or absoluteness.

Understanding the arguments in this way brings Weber very close to the Heideggerian notion of every form of knowledge being a form of concealment, because Weber himself suggested that the content of social science changed as "the light of the great cultural concerns moves on".(22) This is a perfectly reasonable reconstruction of Weber which places it in the general framework of recent Continental philosophy. Weber himself, I would suggest, would not have argued in quite this way, and his strategy in relation to the causal character of historical sciences provides a model that is useful for understanding how he might have responded differently to these issues.

Weber argued that all historical sciences are concerned, at least in some minimal respect, with causal questions, and are thus compelled to deal with the issues that arise out of the problems of applying the notion of causality in the human realm, including the notion of the need for a selection of categories with which to define the causal questions, a problem that cannot be answered in terms of nature and cannot be separated from the language of life.(23) In relation to the question of the grounding of his own methodological conception, I suspect that the most "Weberian" response that could be constructed it would be along the same lines: one which focused on the notion of intelligibility as the common element of the human sciences. The Weberian approach to the problem of collective concepts provides a useful illustration of this kind of reasoning. Weber famously proclaimed himself an enemy 
of collective concepts, but did not do so on metaphysical grounds, either on the grounds of an ontological individualism, or for that matter on the grounds that Popper would later construct as methodological individualism. Instead he argued that collective concepts were explanatorily dispensable for the particular purposes of sociology as he defined them, i.e in terms of "the interpretive understanding of social action and thereby with the causal explanation of its course and consequence", (24) and that from this point of view they were fictions- useful and even, for the practical purposes of such sciences as legal science, necessary, but fictions for sociology. The thrust of his study on the categories of interpretive sociology was to show how one could understand these concepts without claiming they represent realities.

This is not, as in Popper, the result of a methodological decision to see how far one can go in explanation without appealing to collective concepts. But what does it establish? And how? What it seems to establish is the interest-relative character of such concepts- their dependence on special disciplines, such as the presupposition of the notion of legality for dogmatic legal science, or the presupposition of the notion of the state for political science. purpose-relative justifications of the use of collective concepts, rather than ontological or generic "methodological" justifications. This is a conclusion that theorists in these fields have typically attempted to avoid. Philosophers of law in the tradition of Kelsen and Hart, for example, have insisted that certain features of the law, such as the notion of obligation, is factual rather than fictional or "dogmatic" (and that they cannot without circularity be understood as "merely legal") and thus that the subject matter of the law cannot be explained without "changing the subject" if such notions as legal obligation are not recognized as genuine in a non-purpose relative sense.

The contemporary literature on collective intentionality is parallel in structure.(25) One line of argument, which Weber did not address, is that an individualist ontology has no more claim than on our intelligence than a collectivist one, and that any preference for individual over collective ontologies is groundless. How could he have responded? Weber, like some contemporary philosophers, such as Susan Hurley,(26) could have argued that the preference need not be ontological and need not be groundless. Our understanding of individual action and the beliefs of individuals as well as their intentions is for Weber and Hurley clearly superior to our capacity to understand "collective intentions." Thus if a preference for greater degrees of intelligibility, which Weber could argue (parallel to his argument that all of the historical sciences are in some respect concerned with causal relations) is central to the shared purposes of disciplines concerned with human action, is a common ground, then preferring explanations in terms of the beliefs, intentions, and actions of 
individuals, to the extent that it is sufficient for the explanatory purposes in question, is justified by this more basic preference.

When Weber wrote, the situation of the social sciences was such that it might reasonably have been supposed that the various approaches of the social sciences could be integrated, but that one or another of these approaches would prove overwhelmingly more fruitful than the others, and that the methodology of the social sciences could be reduced to the methodology of the most successful approach. It could reasonably have been supposed that some version of the model of natural science could successfully be applied to the social sciences raising the successful application to the status of science, thus freeing it from the limitations which Weber stressed as characteristic of the historical sciences.

Much of social science writing and methodology in the $20^{\text {th }}$ century reflected this idea of integration. But what transpired, despite the aggressive attempts of writers such as Talcott Parsons to prevent it, was a radical fragmentation of approaches, especially in sociology, but to some extent the other social sciences as well, in which different forms of problem constitution generated significant bodies of research scholarship, and constituted their problems in such as way that they could not easily be dismissed as non-scientific, irrelevant, and so forth. In short, methodological and theoretical pluralism established itself in practice, rather than merely in theory.

Nevertheless these approaches were partially circular in just the way that Weber expected. The problems of an empirical nature that arose within them were problems that arose because they were constructed in particular conceptual terms, and there could be no argument of a convincing kind for the exclusive relevance of those particular terms. The social sciences thus became, in the language of the sixties and seventies, following Kuhn, multi-paradigm sciences in which diversity was irremediable and the dream of a single unified science of society or social life receded even in the writings of philosophers of social science themselves.

\section{Normativity and Intelligibility}

The apparent, and partial, exception to this is economics, and the model of rational choice. This model presents today, as it did in Weber's time, a series of puzzles about the fundamental character and logical status of decision theory. And it is in the tangle of issues that arise in the characterization of rationality, with "problems of rationality" as a recent volume of the collected essays of Davidson is entitled,(27) that Weber's present relevance becomes especially apparent. The problems of 
rationality are inter-related, and, for Weber as with Davidson, it is the connectors which link the parts of their thought that are most puzzling and problematic. And it is in comparing the two in this respect that one can see most clearly the coherence of Weber's position, and its distinctiveness.

Begin with some common thoughts between Davidson and Weber: that there is an unbridgeable divide between the language of intentional action, that is to say the language of belief, and the language of scientific law. This means that there can be no "serious science of psychology," as Davidson puts it, meaning a science that actually explains actions, or the rest of the "psychological" domain, in anything like the language of intention and belief. Davidson puts this point in terms of the propositional attitudes (believes that, knows that, fears that, and the like), and says "that there is an irreducible difference between psychological explanations that involve the propositional attitudes and explanations in sciences like physics and physiology.(28) Weber puts this contrast in terms of "subjective meaning," which amounts to essentially the same point: for something to have subjective meaning for someone is to have a propositional attitude toward that thing. They agree as well that action explanation is nevertheless, that is despite not being transformable into the sorts of things that can be explained by laws, as discussed above.

What is not in common is the way they characterize the difference. For Davidson, "the concepts we use to explain and describe thought, speech, and action, are irreducibly normative" (29) Weber of course held the same view, but under the heading of "value-relatedness." For Weber "values" already enter into the descriptions one makes in the language of life.(30) Moreover, Weber thought of ordinary language as the expression of a valuative world outlook, and thus distinctive to the epoch. Thus they agree on the normativity of descriptions of intentional action, but seem to disagree on the reasons for it. Davidson, in "The Very Idea of a Conceptual Scheme," dismisses the idea of distinct conceptual schemes on which Weber appears to rely, and indeed he might have listed Weber, along with Kuhn, as an example of the kind of thinker who, like Kuhn, "is brilliant at saying what things were like before the revolution using- what else- our post-revolutionary idiom." (31) Against this Davidson argues that we could not understand another culture if we do not assume that many of the beliefs of the speakers in another culture are true and like our own, without which we would have no basis for translating and interpreting their beliefs, or even understanding them as beliefs and actions. This would seem to rule out genuinely distinctive Weltanschauungen based on different normativities or values, and indeed, Davidson, in a discussion of the problem of the objectivity of values, embraces the objectivity of values. 
But here the differences are not so great as they initially appear. Weber uses the term Weltanschauung, but he also emphasizes that it is an abstraction, an ideal-type construction of a more complex set of individual beliefs and ideas. And although I have loosely used the term "culture" here to characterize his views, he does nothing to ontologize any of these collective mental concepts, or make them into fixed units, such as paradigms. He does not suppose that the thoughts (including the typifications and schemes of significance) of other people in other eras is always accessible to us, but does take the view that to the extent that they are, they must be accessible through our typifications, though of course these typifications may be refined and abstracted to be made more useful for the purpose of making sense of these other eras. For Weber we are condemned to the scheme of significance of our present, but we can extend it through abstraction.

Where does this leave us with the normativity of rationality, and normativity generally? With respect to the normativity of decision theory, they appear have different views. Weber takes "rationality" to be an ideal-type among others, but primus inter pares with respect to its power to produce intelligibility. Davidson seems to be close to Mises, in making rationality inseparable from action. But there are some ambiguities in each of their formulations that parallel one another and bring them closer together. There is an ambiguity in common, between rationality as something more or less fixed and something more or less local and "ours." For Weber, "logic," which might be taken for him to include calculation and decisiontheory, was non-valuative, in contrast to the domain of described facts of the historical sciences, in which a "valuative" element entered. What is valuative is, for Weber, what is ours: logic is everyone's.

The dilemma is this. For Weber, to acknowledge that the typifications we use in interpretation are not necessarily valid transhistorically is to acknowledge an element of historical relativism. But to acknowledge that what counts as explanation or science for us is also not necessarily valid transhistorically seems to amount to making the methodological or second order claims also historically relative. And this is indeed what the critics of the fact value distinction, such as Strauss, did argue. Davidson's parallel problem is this: if psychology cannot be a "serious science" like physics, is it not merely a restatement of (local) folk psychology with no autonomous claim to empirical validity?

Davidson has a famous answer in general to such concerns which applies to folk psychology: we simply cannot understand the claim that our beliefs might be massively wrong. We can make sense of the claim that one or another of our beliefs is wrong. But we cannot as an interpreter "correctly interpret another speaker [such 
as one from another culture] in such a way that the speaker's beliefs come out massively false inthe interpreters opinion".(32) Folk psychology forms such a large part of our beliefs that it cannot be as a whole massively false. If we meet up with a people whose language appears to lack terms corresponding to our fears that, wants that, and so forth and we could not translate what they do say to mean something that produces more or less similar results, we would simply be unable to translate them at all.

The sceptic who questions whether we might after all be massively wrong is claiming that there could indeed be such a culture. Davidson's point here is similar to his point about rationality. We simply cannot make sense of the claim that the ordinary notion of rationality is false. As with the interpreter of another culture, we cannot even attribute intelligible error to another speaker without relying on it, without assuming that the other speaker is largely in conformity with it.

Weber does not make this claim. As an interpreter, he treated "rationality" as an ideal-type, as something that belongs to us, as part of our language of life and historical period, and for which there are no guarantees that it is transhistorically applicable or applicable to other cultures. But this is not as different a claim than Davidson's as it might appear, despite the fact that Davidson cuts the basic distinctions in a different way. For Weber, the difference is between non-normative logic and values. For Davidson, logic and rationality are "normative" concepts.

But even this distinction turns out to be less significant than it first appears. For Davidson, as a Quinean, even something that we can have no clear idea of what it would be show them to be false, such as the principles of logic or decision-theory, cannot be a priori truths fo us as theorists about the world. In theory at least, something can come along that could compel us to abandon them. But for interpretation, including the interpretation of other cultures, we need less than this notion of rationality: a set of sentences that we can determine to be true, and some inferential connections between them, will enable us to construct a translation manual that allows us to show that the members of the other culture for the most part reason as we do and inhabit the same world.

Davidson, however, sees the problem of values in terms of degrees of dispensability rather than categorical differences. He acknowledges that there are genuine moral conflicts, $(\underline{33})$ which of course are the centerpiece of Weber's "relativistic" discussion of values, and these seem to include Weber's own cases. But he also notes that evaluative attitudes have as their objects propositions that have truth value, $(34)$ and argues that the issues of intelligibility that constrain our interpretations of other cultures arise here as well, so that "the more basic a norm is to our making sense of 
an agent, the less content we can give to the idea that we disagree with respect to that norm." (35) This means that the norms of basic logic don't lend themselves to "disagreement" claims, while the cases of value choice cited by Weber do.

For Davidson, the problem of understanding other cultures is one of understanding their sentences. To understand is to construct a translation manual, something that is not possible unless many of the sentences that are true for them are true for us. But this is a conception that does not require a "theory of meaning" and indeed, as we shall see, precludes an ordinary theory of meaning. Our access to the meaning of their sentences through translation is through determining what sentences they take to be true. But true for Davidson here is true in a Tarskian sense. Thus understanding, more generally, is a matter of triangulation, in which we check utterances against both the conditions we take to be the truth conditions of the sentence and also against the truth conditions that others take to be their truth conditions. This is meaning in a surface sense, and there is no more meaning to be had.

For Weber, the corresponding steps are made in terms of typifications. There is no direct comparison between some sort of independent "reality" and our "typifications," because the objects we are inquired into are already partly conceptualized or typified. But for Weber, the elements of triangulation are implicit in the task, which he stressed, of making sense to a particular historically located audience of intelligibility seeking hearers. Similarly, when in ordinary life we typify the behavior of others, there is a human check on our typifications in the actions that follow from the typification. If we mis-typify in ordinary life, we are likely to discover that our expectations are wrong, and our actions in the rest of the web of typifications based on these wrong expectations will lead to difficulties with others. But for Weber as for Davidson there is no getting beyond useful typifications to essences, or to a "reality" that can serve as a standard. For both of them, the indispensable starting point is with us, and the standards of adequacy of interpretation are necessarily ours. We can refine them, but there is no God's eye view which our refinements will reach.

\section{Notes}

(1) J. S. Mill, A System of Logic, Ratiocinative and Inductive: Being a Connected View of the Principles of Evidence, and the Methods of Scientific Investigation, Collected works of John Stuart Mill ; v. 7-8 (Toronto: University of Toronto Press, 1973-4).

(2) H. H. Bruun, Science, Values, and Politics in Max Weber's Methodology, 
Copenhagen, Munksgaard, 1971.

(3) Leo Strauss, Natural Right and History (Chicago: The University of Chicago Press, 1953).

(4) Alfred Schutz, The Phenomenology of the Social World, trans. George Walsh and Frederick Lehnert (Evanston, IL: Northwestern University Press, [1932]1967).

(5) Michael Friedman, Reconsidering Logical Positivism (Cambridge: Cambridge University Press, 1999) and Michael Friedman, A Parting of the Ways: Carnap, Cassirer, and Heidegger (Chicago: Open Court Publishing Company, 2000).

(6) Ludwig von Mises, Epistemological Problems of Economics, trans. George Reisman (Princeton, NJ: D. Van Nostrand Company, Inc., 1960).

(7) Max Weber, Gesammelte Aufsätze zur Wissenschaftslehre (Tübingen, J. C. B. Mohr, 1988), p. 209.

(8) The connection has been discussed elsewhere, particularly in Stephen Turner, The Search for a Methodology of Social Science in Durkheim, Weber, and the Nineteenth Century Problem of Cause, Probability, and Action, Boston Studies in the Philosophy of Science, 92. (Dordrecht, Holland: Reidel) and Stephen Turner and Regis Factor, Max Weber and the Dispute Over Reason and Value: A Study in Philosophy, Ethics, and Politics (London: Routledge \& Kegan Paul, Ltd, 1984).

(9) Donald Davidson, Mental Events (1970) in his Essays on Actions and Events (Oxford: Claredon Press, 1980), pp. 207-228.

(10) Donald Davidson, Problems in the Explanation of Action (1987) in his Problems of Rationality (Oxford: Oxford University Press, 2004), p. 109.

(11) Davidson, Mental Events, p 225.

(12) Cf. his discussion of emotion and analysis, the two elements of his "causes" of human action, as arising from different parts of the brain, in Donald Davidson, Objectivity and Practical Reason (2000) in his Problems of Rationality (Oxford: Claredon Press, 2004), pp. 52-57.

(13) Donald Davidson, Hempel on Explaining Action (1976) in his Essays on Actions and Events, p. 273.

(14) Donald Davidson, quoted in Pascal Engel, The Norms of the Mental, in Lewis Hahnd, ed. The Philosophy of Donald Davidson (Peru. Illinois: Open Court Publishing, 1999), p. 448.

(15) Donald Davidson, "The Very Idea of a Conceptual Scheme" (1974) in his Inquiries into Truth and Interpretation (Oxford: Clarendon Press, [1974]1984), pp. 183-98.

(16) Karl Popper, The Poverty of Historicism $3^{\text {rd }}$ edn. (New York: Harper and Row [1957]1961). 
(17) M. I. Finley, Ancient History: Evidence and Models (New York: Viking Press, 1986).

(18) The term cultural is not Weber's and is used here as a simplification. As Weber himself says "those 'ideas' that govern the behavior of the population of a given epoch, i.e., which are concretely influential in determining their conduct, can, if a somewhat complicated construct is involved, be formulated precisely only in the form of an ideal-type, since empirically it exists in the minds of an indefinite and constantly changing mass of individuals and assumes in their minds the most multifarious nuances of form, and content, clarity and meaning," Max Weber, The Methodology of the Social Sciences, trans. Edward Shils and Henry A. Finch (Glencoe, IL: Free Press, 1949), pp. 95-96.

(19) Peter Winch, The Idea of a Social Science and its Relation to Philosophy (New York: Humanities Press, 1958).

(20) Max Weber, The Methodology of the Social Sciences, p. 78.

(21) Charles Taylor, Sources of the Self: The Making of Modern Identity (Cambridge, MA: Harvard University Press, 1989); Charles Taylor, Modern Social Imaginaries (Durham, NC: Duke University Press, 2004).

(22) Max Weber, The Methodology of the Social Sciences, pp. 112.

(23) Davidson, as it happens, makes a very similar point about "the dependence of the concept of cause on our interests" He observes that "Science, it is true, strives to overcome the interest relativity of ordinary causality." But goes on to say that "science may without prejudice or circularity note the facts about human nature that reflect interests: the facts about salience, attention,, and tendencies to generalize in some ways rather than others," ie. the common features of our interest in causality". In "Meaning, Truth and Evidence" (1990) in Truth, Language, and History (Oxford: Oxford University Press, 2005), p. 61.

(24) Weber, Max, Economy and Society: An Outline of Interpretive Sociology, 3 vols., Guenther Roth and Claus Wittich eds. (Berkeley and Los Angeles: University of California Press[1968]1978), p. 4.

(25) Raimo Tuomela, The Philosophy of Social Practices : A Collective Acceptance View (Cambridge: Cambridge University Press, 2002) ; John Searle, The Construction of Social Reality (New York: The Free Press, 1995); Margaret Gilbert, "Walking Together: A Paradigmatic Social Phenomenon" in Midwest Studies in Philosophy VI (Notre Dame, IN: Notre Dame University Press, 1996), pp. 1-14; cf. Stephen Turner, What Do We Mean by We?, "Proto Sociology" 18-19 (2003): 13962.

(26) Susan Hurley, Natural Reasons (New York: Oxford University Press, 1989), p. 
157-8.

(27) Donald Davidson, Problems of Rationality (Oxford: Claredon Press, 2004).

(28) Donald Davidson, Problems in the Explanation of Action (1987) in his Problems of Rationality, p.101.

(29) Donald Davidson, Reply to Pascal Engel, Lewis Hahn, ed. The Philosophy of Donald Davidson, p. 460.

(30) A good guess as to what Weber thought about the relation of value and description is to be gained by comparing his to his personal philosophical interlocutor Emil Lask, who struggled with the notion of concept formation, and argued that objects were already partly conceptually constituted for us by the time we could treat them as objects of thought.

(31) Donald Davidson, The Very Idea of a Conceptual Scheme (1974) in his Inquiries into Truth and Interpretation, p. 184.

(32) The quotation is from an explication by Ernest Sosa, Knowledge of Self, Others, World, in Kirk Ludwig, ed. Donald Davidson (Cambridge:Cambridge University Press, 2003), p. 168.

(33) Donald Davidson, The Objectivity of Values (1995) in his Problems of Rationality, p. 41.

(34) Ibid., p. 55.

(35) Ibid., p. 50. 